\title{
MEMS Sensor Measurement of Surface Temperature Response during Subcooled Flow Boiling in a Rectangular Flow Channel
}

\author{
Tomohide Yabuki ${ }^{1, a}$, Randy Samaroo ${ }^{2, b}$, Osamu Nakabeppu ${ }^{3, c}$, \\ Masahiro Kawaji ${ }^{2, d}$ \\ ${ }^{1}$ Kyushu Institute of Technology, Dept. of Mechanical and Control Engineering, Kitakyushu, Japan \\ ${ }^{2}$ Mechanical Engineering Department and the CUNY Energy Institute, City College of New York, \\ New York, USA \\ ${ }^{3}$ Meiji University, Mechanical Engineering Department, Kawasaki, Japan
}

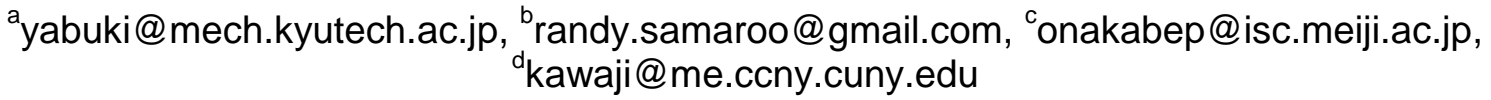

Keywords: Subcooled flow boiling, MEMS sensor, bubble nucleation, bubble departure, microlayer, dryout, wall temperature, liquid subcooling, wall superheat.

\begin{abstract}
Subcooled flow boiling experiments have been conducted using water at atmospheric pressure in a rectangular flow channel. These experiments are conducted in support of a US DOE Nuclear HUB project, the Consortium for Advanced Simulation of Light Water Reactors (CASL). CASL aims at the development of an environment for predictive simulation of light water reactors, and subcooled flow boiling is investigated experimentally in order to develop and validate 3-D Interface Tracking Models (ITMs). In the present experiments, a MEMS sensor has been used to obtain wall temperature response during nucleation, growth and departure of a vapor bubble in subcooled water flowing upward through a vertical rectangular test section. High-speed video images and MEMS sensor data collected at 5,000 fps and $50 \mathrm{kHz}$, respectively, revealed rapid microlayer evaporation, dryout and rewetting phenomena under a single vapor bubble following nucleation accompanied by rapid wall temperature changes of up to $\sim 10 \mathrm{~K}$.
\end{abstract}

\section{Introduction}

Subcooled flow boiling experiments have been conducted using water at atmospheric pressure in a rectangular flow channel. These experiments are conducted for a DOE Nuclear HUB project, the Consortium for Advanced Simulation of Light Water Reactors (CASL). The CASL project (www.ornl.gov/sci/nsed/docs/CASL Project Summary.pdf) aims at the development of an environment for predictive simulation of light water reactors, and subcooled flow boiling needs to be investigated in detail both experimentally and numerically in order to develop and validate 3-D Interface Tracking Models (ITMs) and CFD models which can predict subcooled flow boiling phenomena in fuel assemblies of Pressurized Water Reactors. The data needed for model validation include turbulent liquid flow characteristics, vapor bubble nucleation, growth and departure data, and wall temperature response during subcooled flow boiling.

In previous studies, subcooled flow boiling has been investigated experimentally. Euh et al. [1] measured the bubble departure frequency in water under vertical upflow in an annular channel over a pressure range of $167-346 \mathrm{kPa}$ and liquid subcooling of $7.5-23.4^{\circ} \mathrm{C}$. Situ et al. [2,3] measured the bubble size, growth rate, and departure frequency at atmospheric pressure and inlet water temperature of $80.0-98.5{ }^{\circ} \mathrm{C}$. Basu et al. [4] conducted subcooled flow boiling experiments using a flat plate copper surface and reported that the heat flux and wall superheat required for boiling inception are dependent on the liquid flow rate and subcooling, as well as the contact angle. 
Thorncroft et al. [5] conducted an experiment investigating the bubble size, growth rate, and departure frequency for vertical upflow and downflow in a square duct and pool boiling of FC-87 as the working fluid. Their experiments provided a general understanding of the key differences between upflow, downflow, and pool boiling dynamics. Del Valle and Kenning [6] performed subcooled flow boiling experiments with water at atmospheric pressure on stainless steel. The bubble size and frequency, and the distribution of nucleation sites were measured at high inlet subcooling of $84 \mathrm{~K}$ at heat fluxes corresponding to 70-95\% of the critical heat flux. Samaroo et al. [7] recently reported on the velocity profiles of water flowing past a heated rod in subcooled flow boiling in an annular flow channel.

Regarding the bubble nucleation phenomena, Kandlikar et al. [8] investigated bubble nucleation characteristics in subcooled flow boiling of water at atmospheric pressure using a microscope and high-speed camera. They reported that the model by Bergles and Rohsenow [9] could give the lower limit of wall superheat necessary for bubble nucleation. Basu et al. [4] proposed a correlation for the onset of bubble nucleation based on Hsu's theory [10] and available data that included the effects of surface wetting, system pressure, liquid subcooling and velocity. Basu et al. [4] also developed a correlation for the nucleation site density which depended on the wall superheat and static contact angle but not on the liquid subcooling and velocity.

Finally, there is still little data on the microlayer films below a nucleating bubble. Hollingsworth et al. [11] directly measured the liquid microlayer thickness between sliding cap-shaped bubbles in a static liquid FC-87 and the heated surface. Sliding was induced by pivoting the flow channel between 2-15 from horizontal. Bubbles were between 3 and $8 \mathrm{~mm}$ in length and their Reynolds numbers were between 819 and 2,413. A fiber-optic microlayer thickness probe was utilized alongside stereoscopic high speed video. They obtained microlayer thicknesses between 22 and $55 \mu \mathrm{m}$. These measurements were used to correlate the microlayer thickness with the bubble size and motion. Their work resulted in a new correlation for the microlayer thickness based on a lubrication theory.

In the present experiments, a MEMS sensor has been developed and used to obatin wall temperature response during nucleation, growth and departure of a single vapor bubble in subcooled water at atmospheric pressure flowing upward through a vertical, rectangular test section. High-speed video images and MEMS sensor data were collected at sufficiently high sampling rates to investigate rapid microlayer evaporation, dryout and rewetting phenomena following the nucleation of a single vapor bubble accompanied by rapid wall temperature changes.

\section{Experimental Apparatus}

The experimental apparatus used in this work is shown in Figure 1. It consisted of a 36-Liter stainless steel water storage tank, a minichannel test section made of polycarbonate plates, and drain tank. The test section contained a MEMS sensor to measure the wall temperature response around a vapor bubble nucleation point.

Before each run, deionized water in the storage tank was degassed by boiling for at least 3 hours using two $1 \mathrm{~kW}$ immersion heaters and setting the water temperature at a desired level of liquid subcooling. The top of both the storage tank and drain tank was open to the atmosphere so the water could be circulated through the test section by a gravity head difference between the water levels in the two tanks. The water flow rate was adjusted by two ball valves and measured immediately before each run by collecting the water flowing into the drain tank and measuring the time needed to fill a $500 \mathrm{~mL}$ container. 


\subsection{Rectangular Test Section}

Figure 2 shows a schematic diagram of the test section oriented vertically. Subcooled water flowed upward in the test section from the inlet at the bottom to the outlet at the top which was located 163 $\mathrm{mm}$ above the inlet. The distance from the inlet to the MEMS sensor was $120 \mathrm{~mm}$. The flow channel was rectangular in shape and the cross section was $20 \mathrm{~mm}$ wide and $5.1 \mathrm{~mm}$ thick. Five thermocouples were installed inside the flow channel to measure the bulk liquid temperature. The liquid subcooling was calculated from the temperature obtained by the fourth thermocouple (TC4) closest to the MEMS sensor. The entrance region of the minichannel was heated by an aluminum block containing two embedded cartridge heaters, however, the cartridge heaters were not powered in the present experiments.

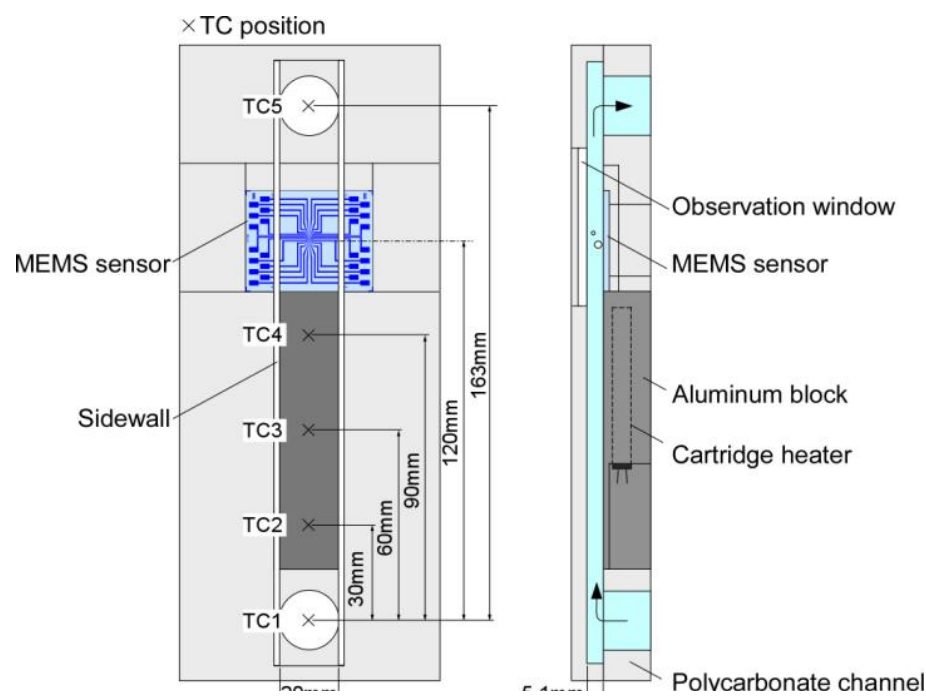

Fig. 2 Schematic diagram of the test section 
The MEMS sensor was fabricated to measure the temperature response of a heated surface. This type of a fast response temperature sensor was previously used by Yabuki and Nakabeppu [12] in pool boiling experiments. A photograph of the MEMS sensor used in this work is shown in Figure 3. The sensor was fabricated on a $180 \mu \mathrm{m}$ thick, $32 \mathrm{~mm} \times 40 \mathrm{~mm}$ silicon wafer covered with a $2 \mu \mathrm{m}$ thick $\mathrm{SiO}_{2}$ layer on both sides. On the front surface (Fig. 3a), a total of six Resistance Temperature Detectors (RTDs) were fabricated by depositing $2 \mu \mathrm{m}$ thick layers of nickel. Two and four RTDs were located upstream and downstream of the electrodes for bubble nucleation trigger, respectively. The bubble nucleation was induced by applying a DC voltage to the two electrodes which caused electrolysis of water at the electrode tip. The layout of the RTDs and nucleation triggering electrodes are shown in a microscope image in Fig. 3c along with the distances between them. The wall temperature measurement area spanned from $150 \mu \mathrm{m}$ upstream to $1,000 \mu \mathrm{m}$ downstream of the nucleation triggering electrodes.

The back face of the MEMS sensor was equipped with two thin films of chromium (Fig. 3b), which were deposited and used to provide Joule heating of the MEMS sensor surface. These thin film heaters were activated during the subcooled flow boiling experiments to provide a constant wall heat flux. At steady state, a superheated liquid layer was formed on the MEMS sensor surface. Then, the bubble nucleation was triggered by applying a DC voltage to the nucleation triggering electrodes. The temperature readings from the RTDs and thermocouples were sampled at $50 \mathrm{kHz}$ and the bubble behavior on the MEMS sensor surface was imaged at 5,000 frames per second using a high speed video camera.

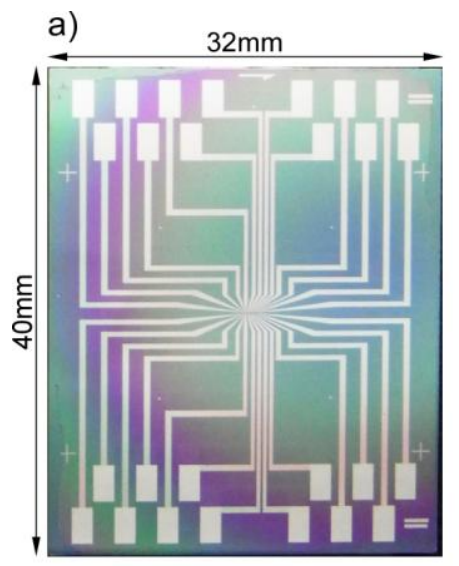

b)

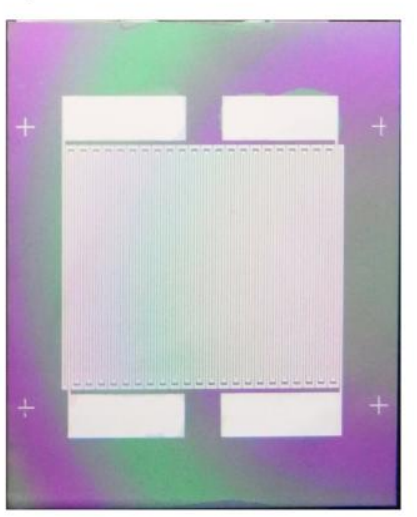

c)

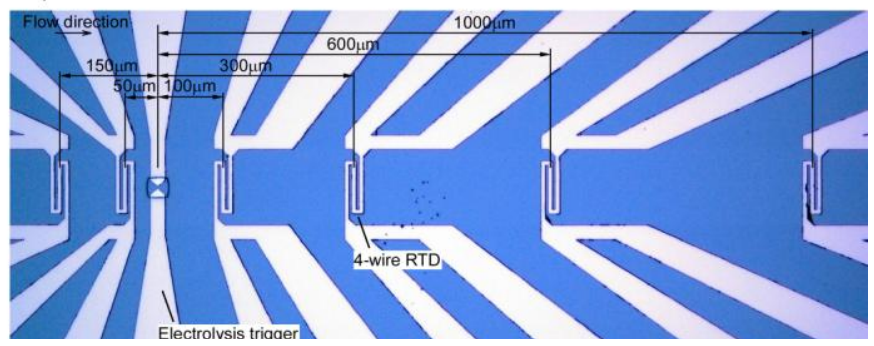

Fig. 3 Photographs of MEMS sensor: a) front face, b) backside, c) microscope image of the front face

The MEMS sensor was calibrated over a temperature range of $65 \sim 99^{\circ} \mathrm{C}$ by circulating water at a constant temperature and recording the sensor readings without applying any heat from the back side. The bulk temperature of water, $T_{b}$, was measured by a thermocouple with an uncertainty of $\pm 1{ }^{\circ} \mathrm{C}$. As shown in Figure 4, the RTD resistances showed a high degree of linearity with temperature up to the bulk temperature of $99{ }^{\circ} \mathrm{C}$, so although they were not calibrated at temperatures above $100{ }^{\circ} \mathrm{C}$, their linearity was considered to extend to $120^{\circ} \mathrm{C}$. Based on the analysis of thermal resistances due to forced convection on the sensor side and heat loss to the ambient air on the back side, the surface temperatures given by the RTD sensors were estimated to be less than the bulk temperature by $1.0{ }^{\circ} \mathrm{C}$ 
at $T_{b}=65{ }^{\circ} \mathrm{C}$ and $2.0{ }^{\circ} \mathrm{C}$ at $T_{b}=99{ }^{\circ} \mathrm{C}$. If the calibration were conducted at a higher temperature, the the surface temperature of $120{ }^{\circ} \mathrm{C}$, the RTD readings were estimated to give temperatures that are higher than the actual surface temperature by $\sim 3.0 \pm 1.0^{\circ} \mathrm{C}$.

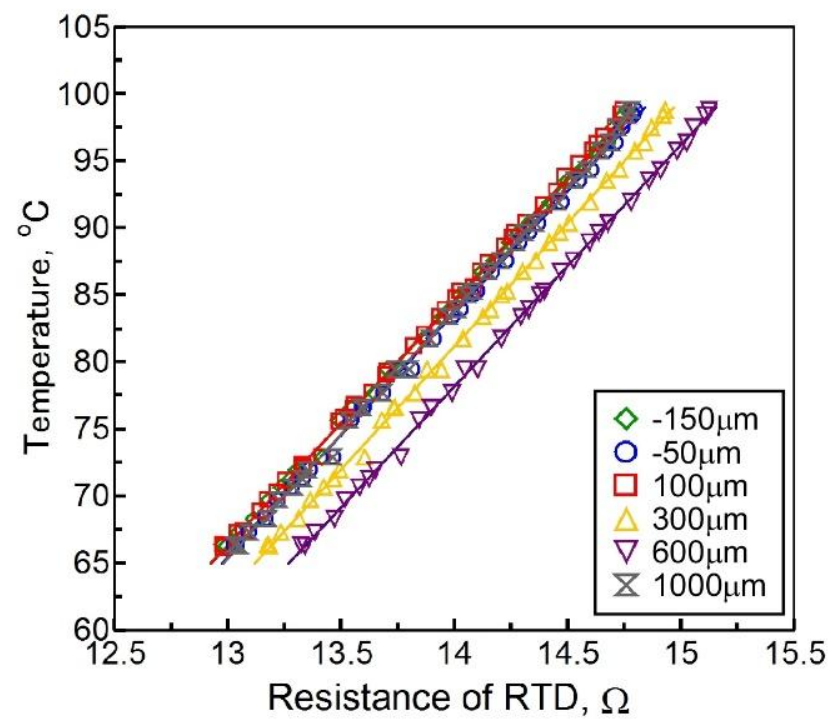

Figure 4. Linear variations of RTD sensor resistances with temperature

\section{Experimental Results and Discussion}

In this paper, the results of two runs with different inlet liquid subcooling $\left(\Delta T_{\text {sub }}=T_{\text {sat }}-T_{\text {liq }}\right)$, wall heat flux $\left(q_{w}\right)$ and resulting wall superheat $\left(\Delta T_{\text {sat }}=T_{\text {wall }}-T_{\text {sat }}\right)$ will be presented. The mass flux was the same at $240 \mathrm{~kg} / \mathrm{m}^{2} \mathrm{~s}$ in both runs, so that the average liquid velocity in the test section was 0.25 $\mathrm{m} / \mathrm{s}$.

In Run \#1, the liquid subcooling just upstream of the MEMS sensor was $\Delta T_{\text {sub }}=5.8 \mathrm{~K}$ and the wall heat flux was $90.4 \mathrm{~kW} / \mathrm{m}^{2}$. The wall superheat, $\Delta T_{\text {sat }}$, based on the average of the six surface temperatures measured just before bubble nucleation was 18K. In Fig. 5, high speed video images of a vapor bubble after nucleation are shown together with the simultaneously measured RTD responses. In order to clearly show the change in the surface temperature before and after the bubble nucleation, the y-axis of Fig. 5 represents the change in the surface temperature $(\Delta T)$ at each RTD location from the value just before the bubble nucleated.

At the instant of bubble nucleation $(t=0)$, the surface temperatures measured by six RTDs show an increase of about $3{ }^{\circ} \mathrm{C}$ from an upstream $(\mathrm{z}=-150 \mu \mathrm{m})$ to downstream $(\mathrm{z}=1,000 \mu \mathrm{m})$ location. Note also that the time scale in Fig. 5 is divided into the first $0-3 \mathrm{~ms}$ in the left hand figure and $3-20 \mathrm{~ms}$ in the right hand figure. A DC voltage was supplied to the nucleation triggering electrodes at $\mathrm{t} \sim-450 \mathrm{~ms}$, and a bubble nucleated at $\mathrm{t}=0$. The first image of the bubble that nucleated is shown in the video image at $\mathrm{t}=0.2 \mathrm{~ms}$. At that time, the wall temperatures at $\mathrm{z}=-150 \mu \mathrm{m},-50 \mu \mathrm{m}$, and $+100 \mu \mathrm{m}$ from the triggering electrodes dropped sharply by $9 \sim 10{ }^{\circ} \mathrm{C}$ from the initial value. The wall temperature at $\mathrm{z}=+300 \mu \mathrm{m}$ also dropped sharply but about $0.15 \mathrm{~ms}$ later than at the former three locations. The wall temperature at $\mathrm{z}=+600 \mu \mathrm{m}$ also started to drop at $0.8 \mathrm{~ms}$ but the magnitude of the temperature drop was only $\sim 1^{\circ} \mathrm{C}$ at $2 \mathrm{~ms}$. The wall temperature at $\mathrm{z}=+1,000 \mu \mathrm{m}$ was essentially unaffected in the first $3 \mathrm{~ms}$, and dropped by $0.5^{\circ} \mathrm{C}$ in $20 \mathrm{~ms}$. In the surface temperature data shown in Fig. 5, the onset of dryout and the beginning of rewetting are indicated by small broken and solid circles, respectively.

As the nucleating bubble grew in size, the RTD locations nearby dried out and the wall temperatures started to rise quickly. The RTD signals at $\mathrm{z}=-50 \mu \mathrm{m}$ and $+100 \mu \mathrm{m}$, and then $+300 \mu \mathrm{m}$ 
show the onset of dry-out at $\mathrm{t}=0.5,0.8$ and $1.2 \mathrm{~ms}$, respectively. The RTD location at $\mathrm{z}=-150 \mu \mathrm{m}$ was judged not to have dried out since there was no surface rewetting observed afterwards.

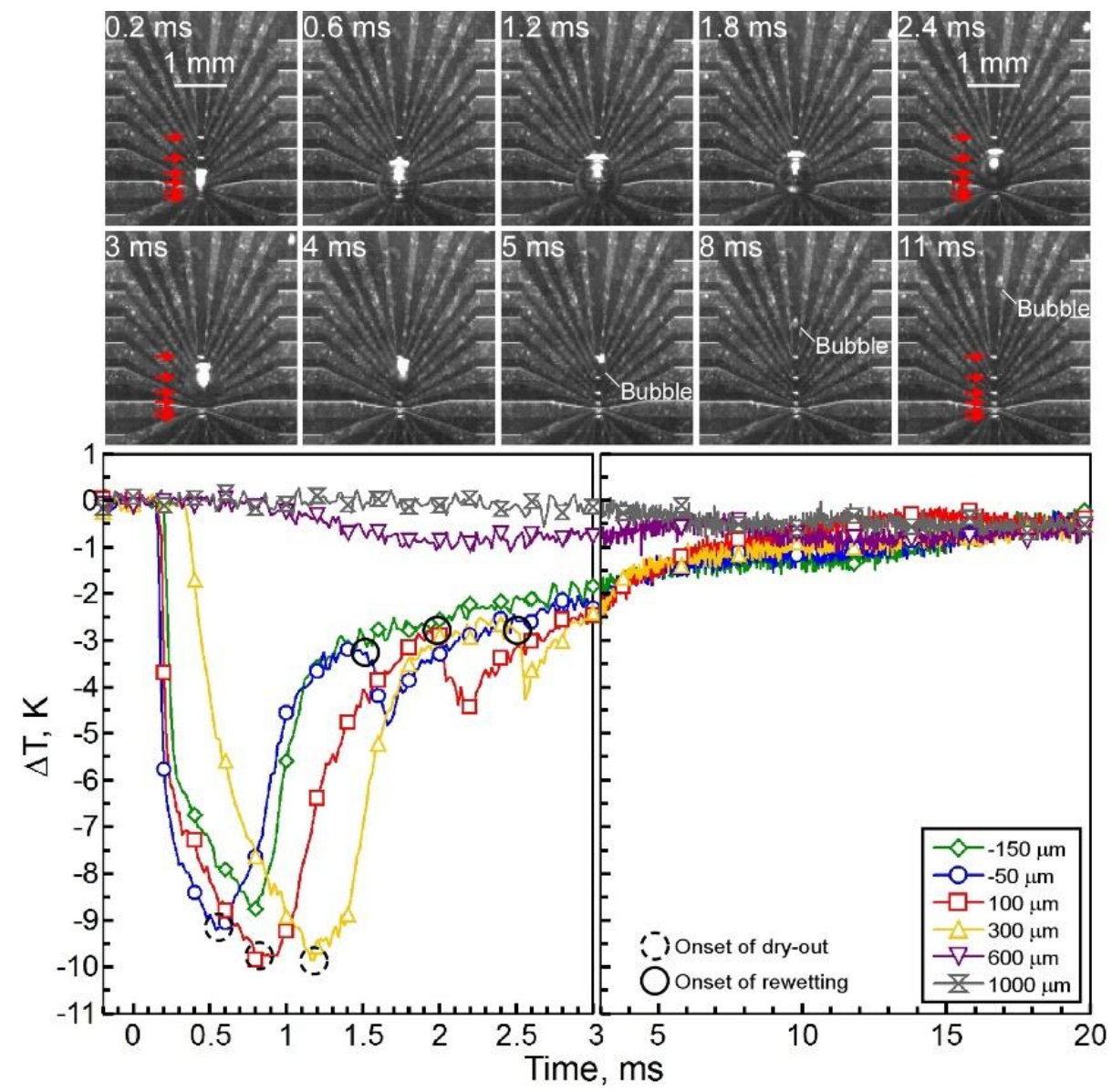

Fig. 5 Bubble behavior and local wall temperature in Run \#1

$$
\left(\Delta T_{s u b}=5.8 \mathrm{~K}, \Delta T_{\text {sat }}=18 \mathrm{~K} \text {, mass flux }=240 \mathrm{~kg} / \mathrm{m}^{2} \mathrm{~s}\right)
$$

In Fig. 6, the positions of the upper edge, $z_{d}$, lower edge, $z_{u}$, and the center, $z_{m}=\left(z_{d}+z_{u}\right) / 2$ of the bubble obtained from the high speed video images are shown. After nucleation, the vapor bubble grew in size due to the evaporation of the superheated microlayer. At $t=1.2 \mathrm{~ms}$, the bubble size reached a maximum of $1.1 \mathrm{~mm}$, but afterwards, it decreased due to condensation of vapor in contact with the subcooled liquid.

The variation of $z_{m}$ with time shown in Fig. 6 indicates the bubble moving downstream with a velocity close to the average liquid velocity of $0.25 \mathrm{~m} / \mathrm{s}$ after departing from the nucleation point at about $\mathrm{t}=2.6 \mathrm{~ms}$. Following the bubble departure, the surface temperature data in Fig. 5 at $\mathrm{z}=-50 \mu \mathrm{m}$, $+100 \mu \mathrm{m}$ and $+300 \mu \mathrm{m}$ show a small dip of $\sim 1.5^{\circ} \mathrm{C}$ indicating the rewetting of the dry-patch occurring at $\mathrm{t}=1.5 \mathrm{~ms}, 2.0 \mathrm{~ms}$ and $2.5 \mathrm{~ms}$, respectively. Since the temperature data at $\mathrm{z}=-150 \mu \mathrm{m}$ did not show rewetting, a dry-patch was not formed at that position after the bubble nucleation. At $\mathrm{z}=-150 \mu \mathrm{m}$, the temperature rise at $\mathrm{t}=0.8 \mathrm{~ms}$ is likely due to a change in the heat transfer mode from a microlayer evaporation to convection to liquid as the contact line was already downstream of this location. The surface temperatures at $\mathrm{z}=+600 \mu \mathrm{m}$ and $+1,000 \mu \mathrm{m}$ did not fall at all, so it is likely that a microlayer did not form. 


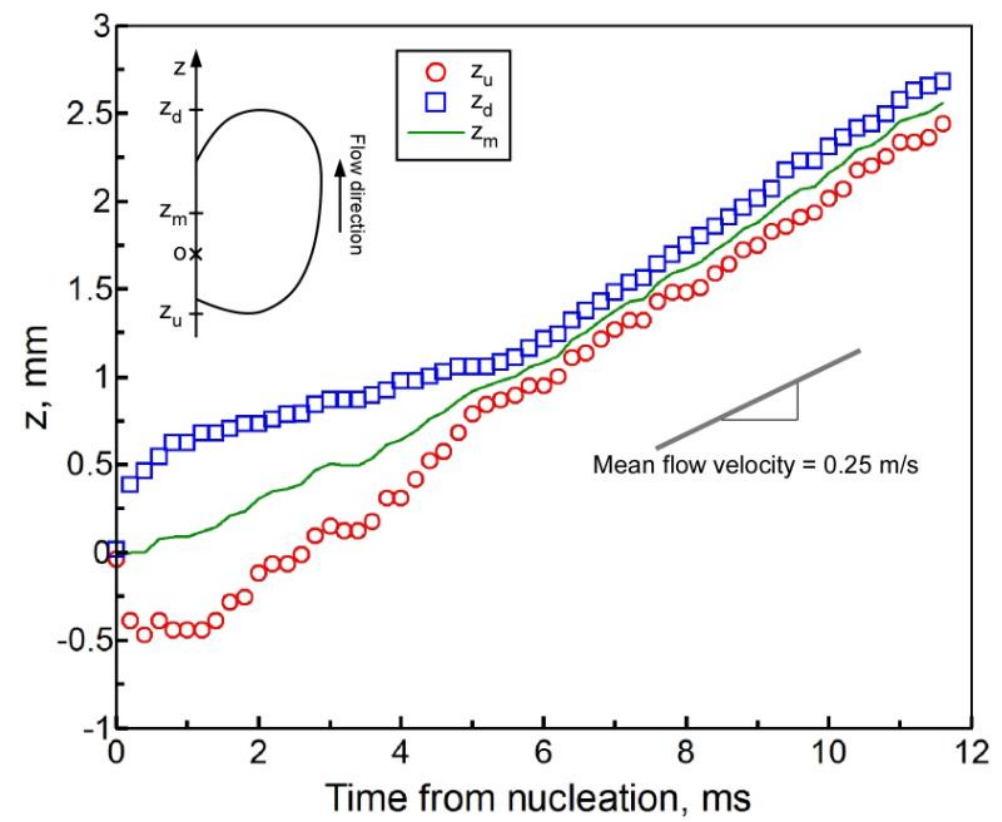

Fig. 6 Motion and dimensions of a vapor bubble in Run \#1

The spatiotemporal behaviors of a microlayer and dry patch under the growing bubble can be obtained from the RTD data and are plotted in Fig. 7 together with $z_{d}, z_{u}$, and $z_{m}$. The microlayer formation is observed to occur spreading outward from the nucleation point. Since the microlayer formed is thinner at locations closer to the nucleation point, it evaporates faster and the dry-patch also spreads outward from the nucleation point. Downstream of the nucleation point at $\mathrm{z}=+100 \mu \mathrm{m}$ and $+300 \mu \mathrm{m}$, the microlayer evaporation occurred for $0.76 \mathrm{~ms}$ and $0.84 \mathrm{~ms}$, respectively, while the dry-patch existed for $1.06 \mathrm{~ms}$ and $1.34 \mathrm{~ms}$, respectively.

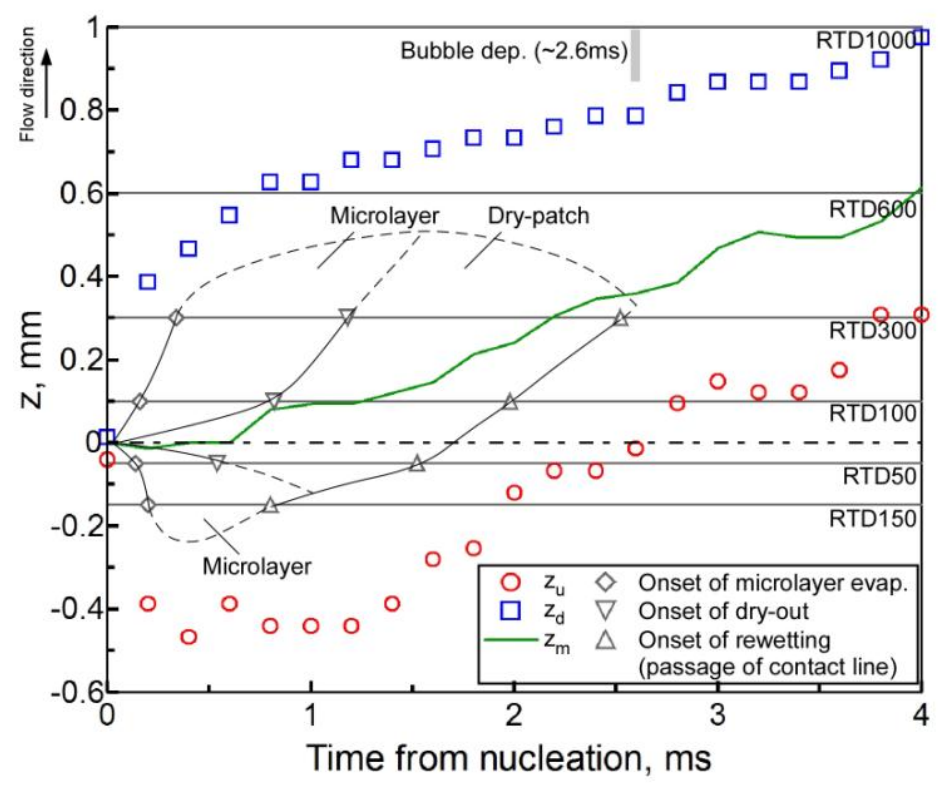

Fig. 7 Spatiotemporal distributions of a microlayer and dry-patch beneath a vapor bubble (Run \#1)

The heat transfer phenomena at the bottom of a nucleating bubble and temperature response of the heater surface obtained in the present flow boiling experiments are similar to those reported for pool boiling on a horizontal heater surface by Yabuki and Nakabeppu [12]. However, the rewetting front was observed to propagate from upstream to downstream in flow boiling, in contrast with the 
inward propagation towards the nucleation point in pool boiling on a horizontal heater surface [12]. To further elucidate the effect of forced convection on the rewetting phenomena in subcooled flow boiling, additional pool boiling experiments need to be conducted using a vertically oriented heater surface embedded with the present MEMS sensor but without any flow.

Next, the data obtained in Run \#2 will be discussed. In this run, the liquid subcooling was increased to $\Delta T_{\text {sub }}=7.4{ }^{\circ} \mathrm{C}$, and the wall heat flux was increased to $105 \mathrm{~kW} / \mathrm{m}^{2}$, so that the wall superheat increased to $\Delta T_{\text {sat }}=20.5{ }^{\circ} \mathrm{C}$. In Fig. 8, high speed video images of a vapor bubble after nucleation and the simultaneously measured RTD responses are shown, while the bubble behavior and size variation are shown in Fig. 9.
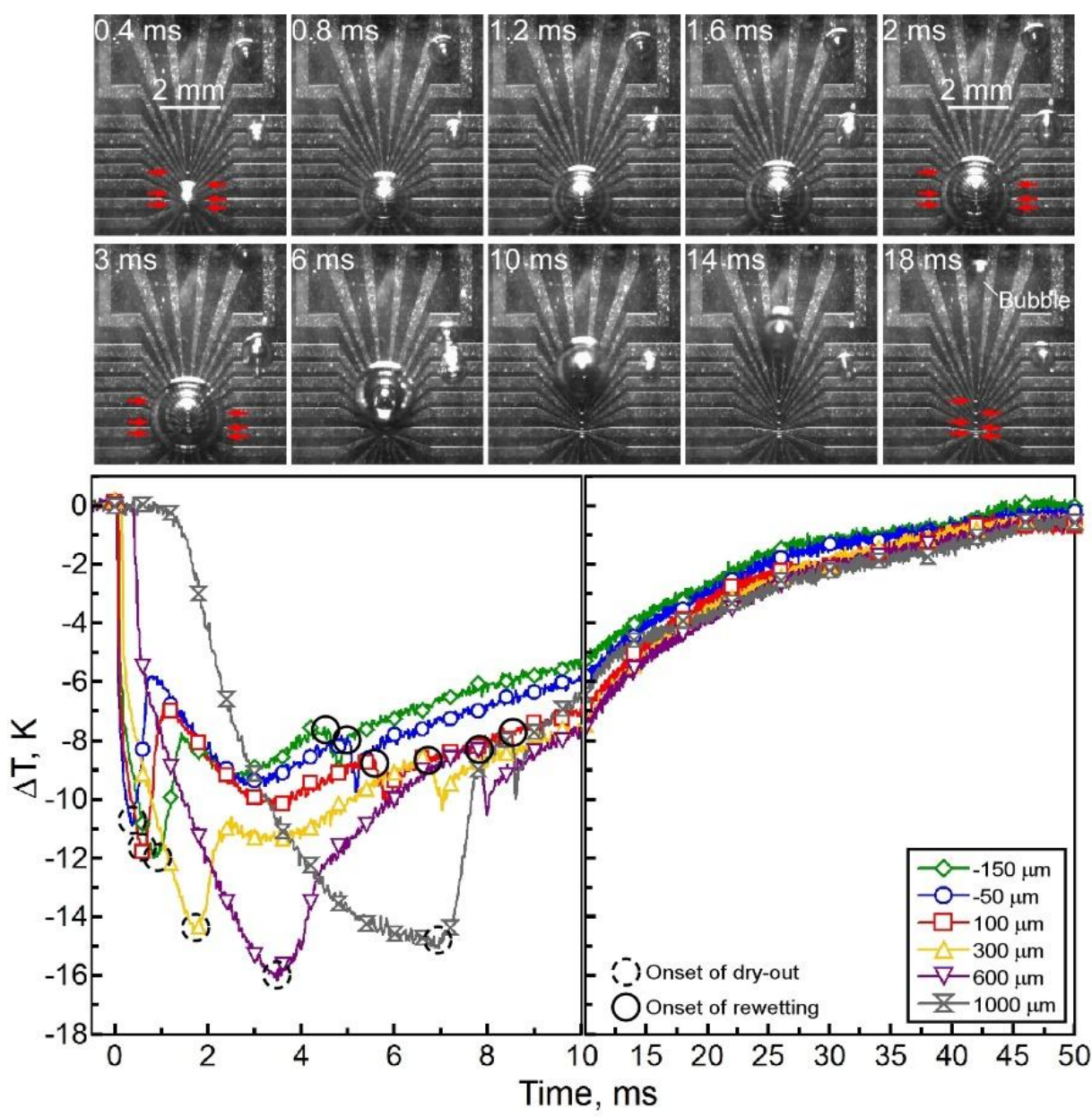

Fig. 8 Bubble behavior and wall temperatures in Run \#2 $\left(\Delta T_{s u b}=7.4 \mathrm{~K}, \Delta T_{\text {sat }}=20.5 \mathrm{~K}\right.$, mass flux $\left.=240 \mathrm{~kg} / \mathrm{m}^{2} \mathrm{~s}\right)$

In Run \#2, a larger bubble was formed (Fig. 8) in comparison with Run \#1 due to the larger wall superheat and thicker superheated liquid layer formed on the MEMS sensor surface. The longitudinal bubble size given by $\left(z_{d}-z_{u}\right)$ reaches a maximum of $2.6 \mathrm{~mm}$ at $\mathrm{t}=3.0 \mathrm{~ms}$ (Fig. 9). Afterwards, the bubble starts to shrink due to condensation but departs from the nucleation point at $\mathrm{t}=$ $10.2 \mathrm{~ms}$. The bubble velocity after departure is close to the mean liquid velocity as in Run \#1. 


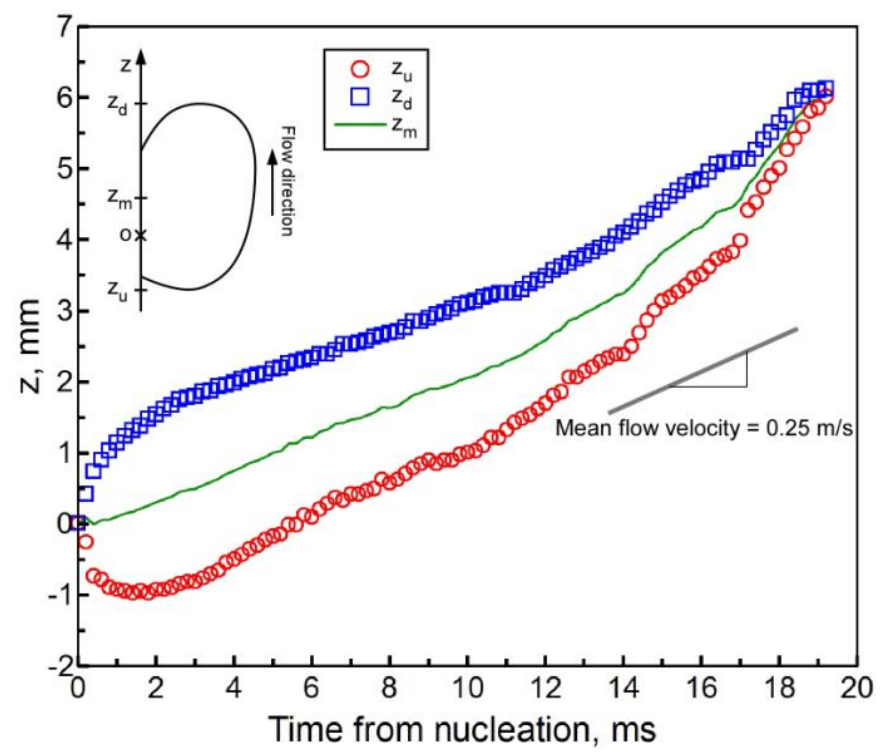

Fig. 9 Motion and dimensions of a vapor bubble in Run \#2

The MEMS sensor data show the formation of a microlayer at all RTD locations from $\mathrm{z}=-150$ $\mu \mathrm{m}$ to $+1,000 \mu \mathrm{m}$, due to the formation of a larger bubble. As a result, microlayer evaporation, dry-patch formation and subsequent rewetting are observed at all the RTD locations. Another difference from Run \#1 that can be noted in Fig. 8 is a temporary drop in the surface temperature observed during the period between dry-out and rewetting at $\mathrm{z}=-150 \mu \mathrm{m},-50 \mu \mathrm{m},+100 \mu \mathrm{m}$ and +300 $\mu \mathrm{m}$. This temporary drop in the wall temperature which was absent in Run \#1 (Fig. 5) could be due to unsteady two-dimensional heat conduction in the MEMS sensor substrate. Because of the high wall-to-fluid heat flux in the microlayer region near the nucleation point, heat is conducted away from the nearby dry-patch where the local wall heat flux is low. This conduction of heat in the solid substrate away from the dry-patch would decrease the rate of temperature rise in the dry-out region and further cause a temporary drop in the wall temperature after the dry-patch formation.

The spatiotemporal variations of the microlayer and dry-patch for Run \#2 are shown in Fig. 10. Both the microlayer region and dry-patch spread out from the nucleation point as in Run \#1. The rewetting of the dry-patch is again observed to propagate in the downstream direction from the nucleation point due to the liquid flow and upward movement of the bubble.

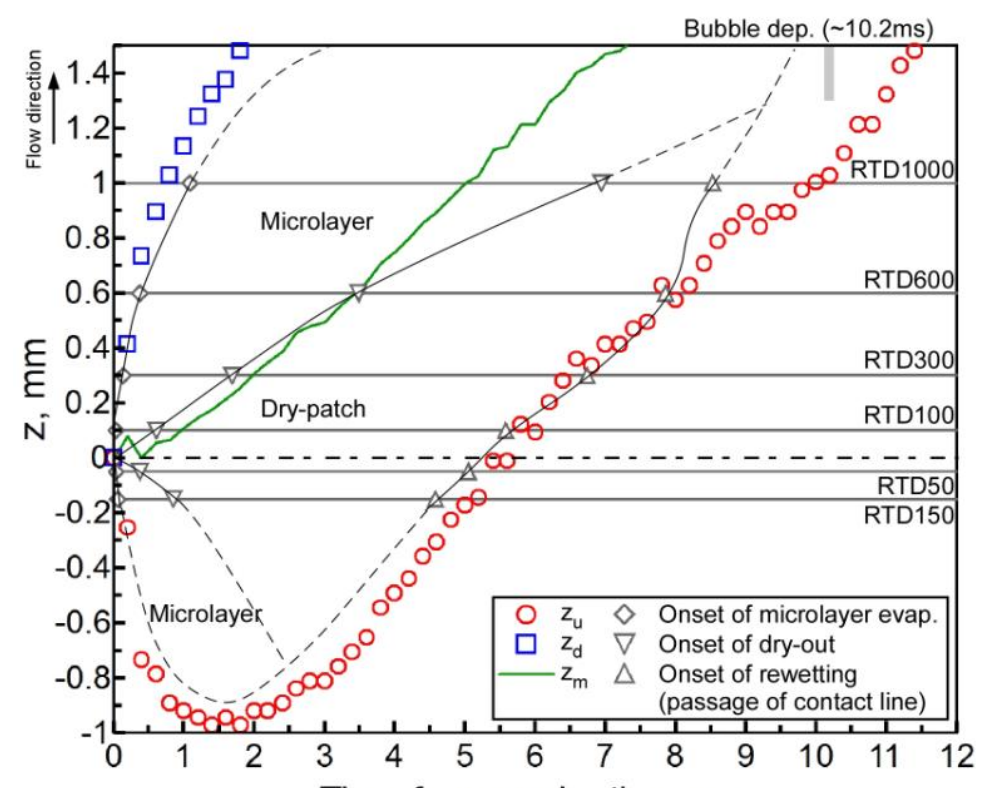

Fig. 10 Spatiotemporal distributions of microlayer and dry-patch under a growing vapor bubble 


\section{Conclusions}

In the present experiment, a MEMS sensor was successfully used to investigate the wall temperature response around a single nucleating vapor bubble during subcooled flow boiling of water in a rectangular flow channel at atmospheric pressure. The mass flux of subcooled water was 240 $\mathrm{kg} / \mathrm{m}^{2} \mathrm{~s}$, and two different liquid subcooling $(5.8$ and $7.4 \mathrm{~K}$ ) and wall heat fluxes $(90.4$ and 105 $\mathrm{kW} / \mathrm{m}^{2}$ ) were used. The RTD signals were recorded at $50 \mathrm{kHz}$ and high speed video images of the nucleating and growing vapor bubble were captured at 5,000 frames per second. From the wall temperature data, rapidly changing phenomena including bubble nucleation, microlayer formation and evaporation and dryout, and subsequent rewetting of the dryout region beneath the bubble could be clearly observed.

In one of the runs, a vapor bubble nucleated, grew in size and departed in less than $3 \mathrm{~ms}$, and the wall temperature dropped by $\sim 10 \mathrm{~K}$ due to microlayer evaporation and partially recovered due to dryout in less than $1 \mathrm{~ms}$. This indicates that the microlayer evaporation and dryout phenomena in subcooled flow boiling can occur in a time scale of $<1 \mathrm{~ms}$, so the use of a MEMS sensor with fast time response is highly useful for studying subcooled flow boiling phenomena in detail. Additional experiments are planned under different mass fluxes, liquid subcooling and wall heat fluxes in order to better understand the subcooled flow boiling phenomena as well as to obtain highly resolved data in time and space which would be useful for validation of numerical simulation tools utilizing Interface Tracking Methods.

\section{Acknowledgements}

The authors would like to acknowledge financial support for this work from Oak Ridge National Laboratory/UT-Battelle, LLC, through a subcontract under the DOE contract DE-AC05-00OR22725.

\section{References}

[1] D. Euh, B. Ozar, T. Hibiki, M. Ishii and C.H. Song, J. of Nuclear Science and Technology, 47, pp. 608-617, 2010.

[2] R. Situ, Y. Mi, M. Ishii and M. Mori, Int. J. Heat Mass Transfer, 47, pp. 3659-3667, 2004.

[3] R. Situ, M. Ishii, T. Hibiki, J.Y. Tu, G.H. Yeoh and M. Mori, Int. J. Heat Mass Transfer, 51, pp. 6268-6282, 2008.

[4] N. Basu, G. R. Warrier and V. K. Dhir, ASME J. Heat Transfer, 124, pp. 717-728, 2002.

[5] G.E. Thorncroft, J.F. Klausner and R. Mei, Int. J. Heat Mass Transfer, 41, pp. 3857-3871, 1998.

[6] M.V.H. Del Valle and D.B.R. Kenning, Int. J. Heat Mass Transfer, 28, pp. 1907-1920, 1985.

[7] R. Samaroo, N. Kaur, K. Itoh, T. Lee, S. Banerjee, and M. Kawaji, Nuclear Engineering and Design, 268, pp. 203-214, 2014.

[8] S. G. Kandlikar, V. Mizo, M. Cartwright, and E. Ikenze, ASME Proc. of 32nd National Heat Transfer Conference, 4, pp. 11-18, 1994.

[9] A.E. Bergles and W. M. Rohsenow, Trans. ASME, Series C, 86(3), pp. 365-372, 1964.

[10] Y.Y. Hsu, Journal of Heat Transfer, 84, pp. 207-216, 1962.

[11] D.K. Hollingsworth, X. Li, and L.C. Witte, Journal of Heat Transfer, 130.11 (2008): 111501.

[12] T. Yabuki and O. Nakabeppu, Int. J. Heat Mass Transfer, 76, pp. 286-297, 2014. 